Frieman, J. P., Rohrbaugh, M. \& Riccio, D. C. Age differences in the control of acquired fear by tone. Canadian Journal of Psychology, 1969, 23, 237-244.

Frieman, J. P., Warner, J. \& Riccio, D. C. Age differences in conditioning and generalization of fear in young and adult rats. Developmental Psychology, 1970, 3, 119-123.

Kirby, R. H. Acquisition, extinction and retention of an avoidance response as a function of age. Journal of Comparative and Physiological Psychology, 1963, 56, 158-162.

Rohrbaugh, M. \& Riccio, D. C. Stimulus generalization of learned fear in infant and adult rats. Journal of Comparative and Physiological Psychology, 1968, 66, 530-533.
Rundle, G. P., Niemi, R. \& Thompson, W. R. Sensory preconditioning effects in young and adult rats. Canadian Journal of Psychology, 1971, 25, 323-325.

Snedden, D. S., Spevak, A. A., \& Thompson, W. R. Conditioned and unconditioned suppression as a function of age in rats. Canadian Journal of Psychology, 1971, 25, 313-322.

Vanderwolf, C. H., \& Vanderwolf, M. L. Relations of heart rate to motor activity and arousal in the rat. Canadian Journal of Psychology, 1970, 24, 434-442.

Winer, B. J. Statistical Principles in experimental design. New York: McGraw-Hill.

(Received for publication Novem ber 25, 1974.)

\title{
Temporal contiguity: Is it a sufficient condition for reinforcement?
}

\author{
ROBERT G. HARRISON \\ Anclote Manor, Tarpon Springs, Florida 33589 \\ and \\ ROBERT W. SCHAEFFER \\ Auburn University, Auburn, Alabama 36830.
}

\begin{abstract}
Utilizing an experimental paradigm described by Premack, an attempt was made to determine whether temporal contiguity between differentially probable responses was a sufficient condition for reinforcement. Using six rats as subjects, and running in an activity wheel and drinking a sucrose solution as responses, it was determined that mere temporal contiguity of a high probability response subsequent to a low probability responses was not a sufficient condition for reinforcement. These data were discussed with respect to important procedural questions regarding appropriate response baseline referents from which reinforced increments in responding are to be inferred.
\end{abstract}

Herrnstein (1966) and Sidman (1960) have maintained that temporal contiguity alone is a sufficient condition for reinforcement to occur and have cited Skinner's (1948) classic paper on superstitious behavior in the pigeon as conclusive evidence for this allegation. Premack (1965) has observed, however, that the reinforcement relationship typically includes, in addition to the readily recognized factor of temporal contiguity, three additional, but less commonly recognized, experimenter-imposed conditions: (1) an instrumental response requirement, (2) a reduction in the amount or duration of reinforced responding, and (3) a circumscribing of the response distribution permitted for reinforced responding. The minimal condition required to determine the role of temporal contiguity in the reinforcement relation, according to Premack, would involve the mere temporal pairing of $\mathrm{L}$, a low probability response, and $\mathrm{H}$, a high probability response, without

The research for this paper was supported by Public Health Research Grants $\mathrm{MH}-08775$ and $\mathrm{MH}-12025$ from the National Institute of Mental Health, R. W. Schaeffer, principal investigator. any of the other three experimenter-imposed conditions present. Such a minimal case would occur when both $\mathrm{L}$ and $\mathrm{H}$ are freely and concurrently available, given that $\mathrm{H}$ follows $\mathrm{L}$ in close temporal proximity on one or more occasions. To test this hypothesis, Premack (1965) arranged a behavioral condition in which only running (L) or licking $(\mathrm{H})$ was available (i.e., a single baseline) to determine the independent probability of each response, then made $\mathrm{L}$ and $\mathrm{H}$ freely and concurrently available (i.e., a paired baseline), and finally tested the probabibility of running (L) alone in an "extinction" phase. Relative to total running in the single baseline, total running in the paired baseline was less; during "extinction," the probability of running did not differ significantly from the probability of running in the initial single baseline condition. Premack concluded that (a) no reinforcement had occurred in the paired baseline conditions in spite of frequent temporal contacts between the two responses and (b) temporal contiguity could not, therefore, be labeled a sufficient condition for reinforcement to occur.

Although Premack (1965) utilized the single baseline 


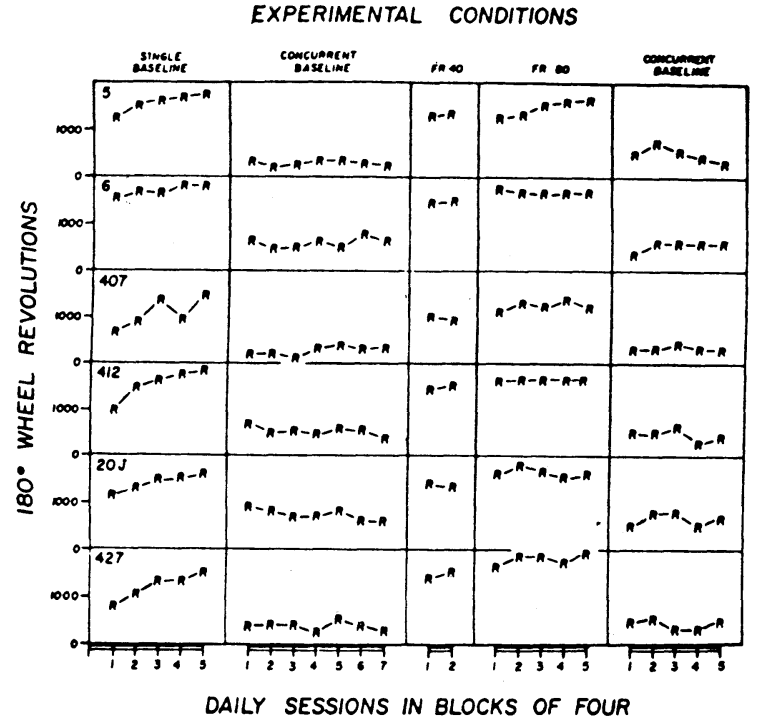

Figure 1. 180-deg wheel revolutions as a function of sessions across experimental conditions for all subjects.

as the reinforcement referent in his study, he has indicated that a concurrent baseline is the appropriate referent from which the effects of reinforcement in the contingency should be evaluated. Comparing response probabilities in single and paired baselines, he noted that: "(1) frequency of responding to any item is apparently always less when the item is paired with another (nonzero) item than when it is presented alone, but (2) the ordinal relations among items are not disturbed simply by the pairing procedure (Premack, 1965 , p. 137)." Premack's (1965) study thus seems to raise as many questions as it was designed to answer since the particular baseline chosen as a reinforcement referent obviously will determine if reinforcement has or has not occurred. If, indeed, instrumental response probabilities in the paired baseline are always lower than in the single baseline, reinforced response increments, computed relative to the paired baseline, may actually reflect asymptotic contingent instrumental responding that does not exceed instrumental responding in the single baseline! Since it seems important to determine the relation between single and paired baselines and the effects of reinforcement, the present study, which is an extension of Premack's (1965) study, was undertaken.

\section{METHOD}

\section{Subjects}

Six albino female Dublin SDD/DR rats, approximately 250 days old, with an experimental history of running and licking baselines and run-to-lick contingencies, were individually housed, given free access to food, and placed on a 22-h fluid deprivation schedule. A $10 \%$ sucrose solution was available in the experimental chambers during the daily 1 -h sessions, and 1 -h free access to water was given in the home cage following each session.

\section{Apparatus}

Experimental chambers were modified Wahmann activity wheels (Schaeffer, 1966) with both lick contacts and 180-deg wheel revolutions being recorded by Esterline-Angus analog-digital operations recorders. Fluid ingestion was recorded directly from graduated $100-\mathrm{ml}$ cylinders.

\section{Procedure}

In the first (single baseline) phase of the experiment, the 1-h session was divided into two equal periods; only running was available in the first $1 / 2 \mathrm{~h}$; only licking was available in the second $1 / 2 \mathrm{~h}$. On alternate days, licking was available in the first $1 / 2 \mathrm{~h}$; running was available in the second $1 / 2 \mathrm{~h}$. When mean responding (for both responses) for the last four sessions minus mean responding in the preceding four sessions divided by mean responding in the last eight sessions did not exceed $20 \%$, responding was considered stable. This stability criterion was employed throughout the experiment.

In the second (paired baseline) phase, both running and licking were freely and concurrently available for the entire 1 -h session. The third (FR) phase, in which drinking (H) was contingent upon running (L), consisted of FR 40 ( $1 / 2$ wheel-turns) for 8 days and then FR 80 ( $1 / 2$ wheel-turns) until response stability was attained. Completion of either FR requirement made the drinking tube available for $10 \mathrm{sec}$. The fourth (paired baseline) phase was identical to the second phase of the experiment.

\section{RESULTS}

Figure 1 shows mean $1 / 2$ wheel-turns for all animals across the experimental conditions in blocks of four daily sessions. Statistical analyses, including Duncan's multiple range test, of the data shown in Figure 1

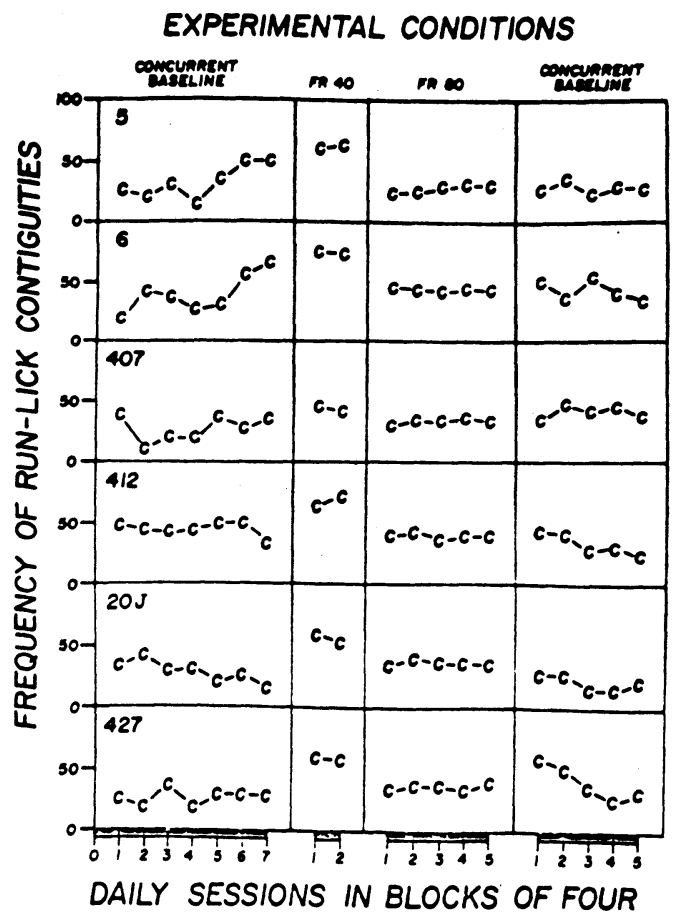

Figure 2. Mean frequency of run-lick contiguities as a function of sessions across experimental conditions for all subjects. 
supported the following conclusions.

First, running in the first paired baseline condition did not differ significantly from running in the second paired baseline condition. For five subjects, the $\mathrm{p}$ value obtained was greater than .05 . For Subject 427, p $<.05$ but $>.01$.

Secondly, running in both the first and second paired baseline conditions was significantly less than the amount run in the single baseline condition for all six subjects $(p<.01)$. Running under both the FR 40 and FR 80 contingencies was significantly greater than running in both concurrent baseline conditions for all subjects $(\mathrm{p}<.01)$. For four of the subjects, the total amount run in the FR 80 condition did not differ significantly from the total amount run in the single baseline condition $(p>.05)$. Subject 412 ran significantly more in the single baseline condition than in the FR 80 condition $(\mathrm{p}<.01)$, whereas Subject 427 ran significantly more in the FR 80 condition than in the single baseline condition $(p<.01)$.

Thus, these results indicate that running in the single baseline condition exceeded running in the paired baseline conditions. All six subjects showed an increment in running in the contingency conditions, relative to the amount run in either pre- or postcontingency paired baseline conditions. However, only one subject showed an increment in instrumental running when the increment in running was defined with reference to the single baseline condition.

\section{DISCUSSION}

Whether single or paired baselines are the appropriate referent from which reinforced increments in responding are to be evaluated is important for all experimenters employing instrumental responses with precontingent probabilities substantially greater than zero. If reinforcement is defined solely in terms of the increments afforded the instrumental response as a function of the reinforcement contingency, then the results of the present experiment clearly show that the rate of the instrumental response in the paired baseline condition is the only reasonable referent for inferring reinforced increments in instrumental responding.

The decrement in running which occurred when the subjects were shifted from the single baseline condition to the paired baseline condition has been previously observed by Premack (1965), who argued that response competition between $\mathrm{L}$ and $\mathrm{H}$ could not account for the decrement in $L$. Response competition. could explain the decrement in L only if the total amount of time spent in $\mathrm{L}$ and the total amount of time spent in $\mathrm{H}$ in the single baseline conditions exceeded total available session time in the paired baseline condition. When making these calculations, Premack found that the totals of $\mathrm{L}$ and $\mathrm{H}$ time were substantially less than total session time available in the paired baseline condition and thus discarded response competition as an explanation of the change in probability of L. A similar result was obtained in the present experiment; the sum of lick time and run time in the single baseline conditions only accounted for at most approximately $80 \%$ of the total time available in each of the two $1 / 2-h$ segments of each daily session.

The present conclusion that the single baseline is not an appropriate referent from which to evaluate reinforced increments in responding in the contingency situation bears directly upon the question whether pure temporal contiguity of $\mathrm{L}$ and $\mathrm{H}$ will produce an increment in $\mathrm{L}$. If a very powerful condition (the if A then B contingency) which guarantees $100 \%$ temporal correlation between $\mathrm{L}$ and $\mathrm{H}$ was not sufficient to produce increments in $\mathrm{L}$ over single baseline probability levels, why should the much less powerful adventitious correlation of $L$ and $\mathrm{H}$ (which is usually less than $100 \%$ ) be expected to produce increments in $L$ relative to the single baseline? Since the single baseline is not appropriate for evaluating the reinforcement effects of the programmed contingency relationship, it could not possibly be appropriate for evaluating the less powerful effects of adventitious reinforcement. Thus, it is not surprising that Premack (1965) did not obtain reinforced response increments due to mere temporal contiguity of $\mathrm{L}$ and $\mathrm{H}$, when he used the single baseline as his reinforcement referent.

To evaluate the possible reinforcing effects of adventitious temporal contiguity in this study, Esterline-Angus records were sampled, and frequency counts made of the number of times that licking $(\mathrm{H})$ occurred in the 20 -sec period following running (L). As is evident in Figure 2, the mean number of adventitious $\mathrm{L}-\mathrm{H}$ occurrences in the concurrent baseline condition essentially equalled the number of L-H pairings in the actual contingency. The correlation between $\mathrm{L}-\mathrm{H}$ pairings in the paired baseline conditions would be obviously of sufficient magnitude to produce reinforcement, if mere temporal contiguity is a sufficient condition for reinforcement to occur. The question is: How may reinforcement be defined and detected?

If reinforcement is defined as an increment in $\mathrm{L}$ over the single baseline level, then no reinforcement occurred in the paired baseline condition in the present experiment. Since, as has been shown above, the single baseline is not an appropriate referent for evaluating reinforcement effects, even in the contingency condition, no decision may be made from comparisons of single and concurrent baseline probabilities, in the present experiment, as to whether mere temporal contiguity is or is not a sufficient condition for the occurrence of reinforcement.

If temporal contiguity were a sufficient condition for reinforcement to occur, then comparisons across the first through the nth concurrent baseline sessions should reveal progressive and systematic increases in both the frequency of L-H pairings and in the probability of L. Premack (1965) found no systematic changes in the probability of $\mathrm{L}$ across concurrent baseline sessions; the present data (cf. Figure 1 and 2) replicate his findings.

Clearly, the evidence presented by the present experiment does not contradict Premack's (1965) contention that mere temporal contiguity is not a sufficient condition for the occurrence of reinforcement. The results of the present experiment do, however, point out both the practical and theoretical necessity of more adequate delineation of the appropriate baseline referent from which reinforced increments in responding are to be inferred.

\section{REFERENCES}

Herrnstein, R. J. Superstition: A corollary of the principles of operant conditioning. In W. K. Honig (Ed.), Operant behavior: Areas of research and application. New York: Appleton-Century-Crofts, 1966.

Premack, D. Reinforcement theory. In D. Levine (Ed.), Nebraska symposium on motivation, 1965. Lincoln, Nebraska: University of Nebraska Press, 1965.

Schaeffer, R. W. A new device for programming contingencies between drinking, running, and lever-pressing. Journal of the Experimental Analysis of Behavior, 1966, 9, 529-533.

Sidman, M. Tactics of scientific research. New York: Basic Books, 1960.

Skinner, B. F. 'Superstition' in the pigeon. Journal of Experimental Psychology, 1948, 38, 168-172.

(Received for publication December $5,1974$. ) 